\title{
Direct Crossed-Aldol Reaction of Acetaldehyde
}
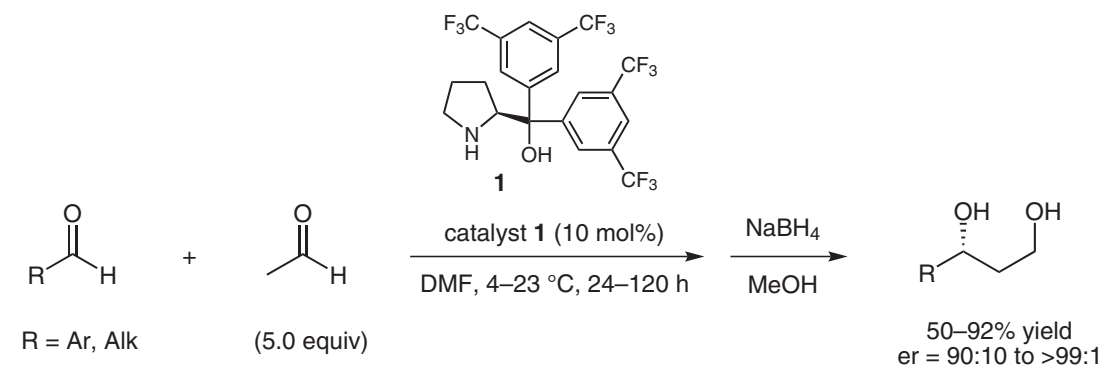

Selected examples:

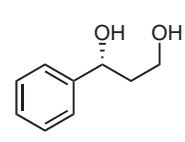

$53 \%$ yield er > 99:1<smiles>OCCC(O)c1cc(C(F)(F)F)cc(C(F)(F)F)c1</smiles>

\section{$76 \%$ yield} er > 99:1<smiles>OCCC(O)c1ccncc1</smiles>

$83 \%$ yield er > 99:1 $50-92 \%$ yield
er $=90: 10$ to $>99: 1$

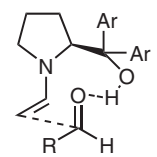

proposed TS
Significance: The authors report an organocatalytic asymmetric direct crossed-aldol reaction of acetaldehyde. Diaryl prolinol $\mathbf{1}$ was found to be an effective catalyst and DMF the best solvent for this reaction. Due to the instability of the aldol products they were reduced to the corresponding diols. With 10 mol\% of catalyst 1 and 5 equivalents of acetaldehyde, good to high yields (50-92\%) and excellent enantioselectivities (er $=98: 2$ to $>99: 1)$ are obtained for different aromatic aldehydes. One aliphatic aldehyde was also used and reasonable enantioselectivity (er $=90: 10)$ was obtained.
Comment: Although organocatalytic aldol reactions with acetaldeyhde were early attempted by the groups of Barbas (J. Org. Chem. 2002, 67, 301) and Jørgensen (Chem. Commun. 2002, 621), the desired products were obtained in poor yields or enantioselectivities. In that respect, this report by the authors is very important. It is intriguing that proline, which is the usual catalyst for other aldol reactions, was found to be ineffective in this case. For an independent use of acetaldehyde in Mannich reactions by List and co-workers, see: Nature 2008, 452, 453 and also Synfacts 2008, 532. 